\title{
Don Quixote: el legado coreográfico de Petipa
}

Mtra. Gabriela Estrada

Universidad de Sonora

getflamenco@gmail.com

\section{Introducción}

En el 2015 celebramos el cuarto centeInario de la joya literaria de Miguel de Cervantes Saavedra, cuya segunda parte, El ingenioso caballero don Quijote de la Mancha vio la luz en 1615. Esta obra magna ha motivado la creación de numerosas representaciones escénicas y dancísticas desde la primera década del siglo XVII , pero sin lugar a duda, la propuesta de Marius Petipa ha sido la de mayor trascendencia histórica. Su coreografía, estrenada con el Ballet Imperial en el Teatro Bolshoi de Moscú el 26 de Diciembre de 1869 y expandida por él mismo en 1871, continúa vigente en la cartelera de las principales compañías de ballet a nivel internacional. La relevancia coreográfica de Don Quixote también reside en ser el ballet de temática española más representado del repertorio actual.

A través de este artículo podremos valorar la influencia artístico-cultural de la danza española en el repertorio del ballet a través del legado coreográfico de temática española de Marius Petipa (1818-1910), particularmente Don Quixote. Para ello, daremos seguimiento a los puntos de convergencia de elementos de la danza española en la carrera de Petipa pertinentes a su trienio en España, apoyándonos principalmente en el testimonio de sus memorias. Con ello, aunado con el legado de repertorio coreográfico de temática española de figuras monumentales como Léonide Massine (1836-1979), Rolad Petit (1924-2011) y Alberto Alonso (19182008), comprenderemos las motivaciones que han impulsado la inclusión de la danza española, e inclusive el flamenco, en los programas de estudio de las escuelas afiliadas a las principales compañías de ballet.

\section{Propuestas escénicas a partir de Don Quixote}

Haciendo un recorrido histórico a lo largo de esta última centuria, podemos observar el desarrollo de múltiples propuestas escénicas a partir de la plantilla coreográfica de Don Quixote de Marius Petipa, aunque, inevitablemente, la esencia de su creación se ha ido diluyendo en el proceso. Maya Plisetskaya, cuyo protagonismo en el papel de Kitri quedó enmarcado como hito, subraya que en las reposiciones actuales de Don Quixote queda poco de la coreografía original de Petipa, prevaleciendo los ajustes coreográficos que Alexander Gorsky le hiciera a la obra en 1900. De hecho, el mismo Petipa lamentaba en su época las modificaciones "disparatadas" que sus obras sufrían, como el caso de su propuesta para la ópera Carmen:

. . . una vez sucedió que caí enfermo, y el Sr. director expresó el deseo de que se sustituyera ese baile por otro pas "más españolizado" e inventaron aquí algo disparatado que parecía más bien, puedo asegurarles, un baile chino que español. . . o o es posible que no comprendieran que mi fantasía aquí no tenía nada que ver, que el baile era auténtico y que lo aprendí en Madrid (Petipa, Mémoires, 1990). 
Como testifica el mismo coreógrafo, este contaba con un conocimiento del baile y cultura española adquirido durante tres años de inmersión artístico-cultural en España. Fue precisamente en junio de 1844 que Marius Petipa dejó Burdeos para pasar a figurar al Gran Teatro del Circo de Madrid, aportando su talento dancístico en España hasta enero de 1847. Durante ese período, Petipa también aprendió e interpretó bailes populares españoles pre-flamencos, creando un copioso repertorio de variaciones y ballets de temática española, entre ellos: $L a$ Perla de Sevilla (1844), Aventuras de una hija de Madrid (1844), Camino a la corrida de toros (1845), y Carmen y su torero (1846). De manera particular, durante la gira que realizó de abril a julio de 1846

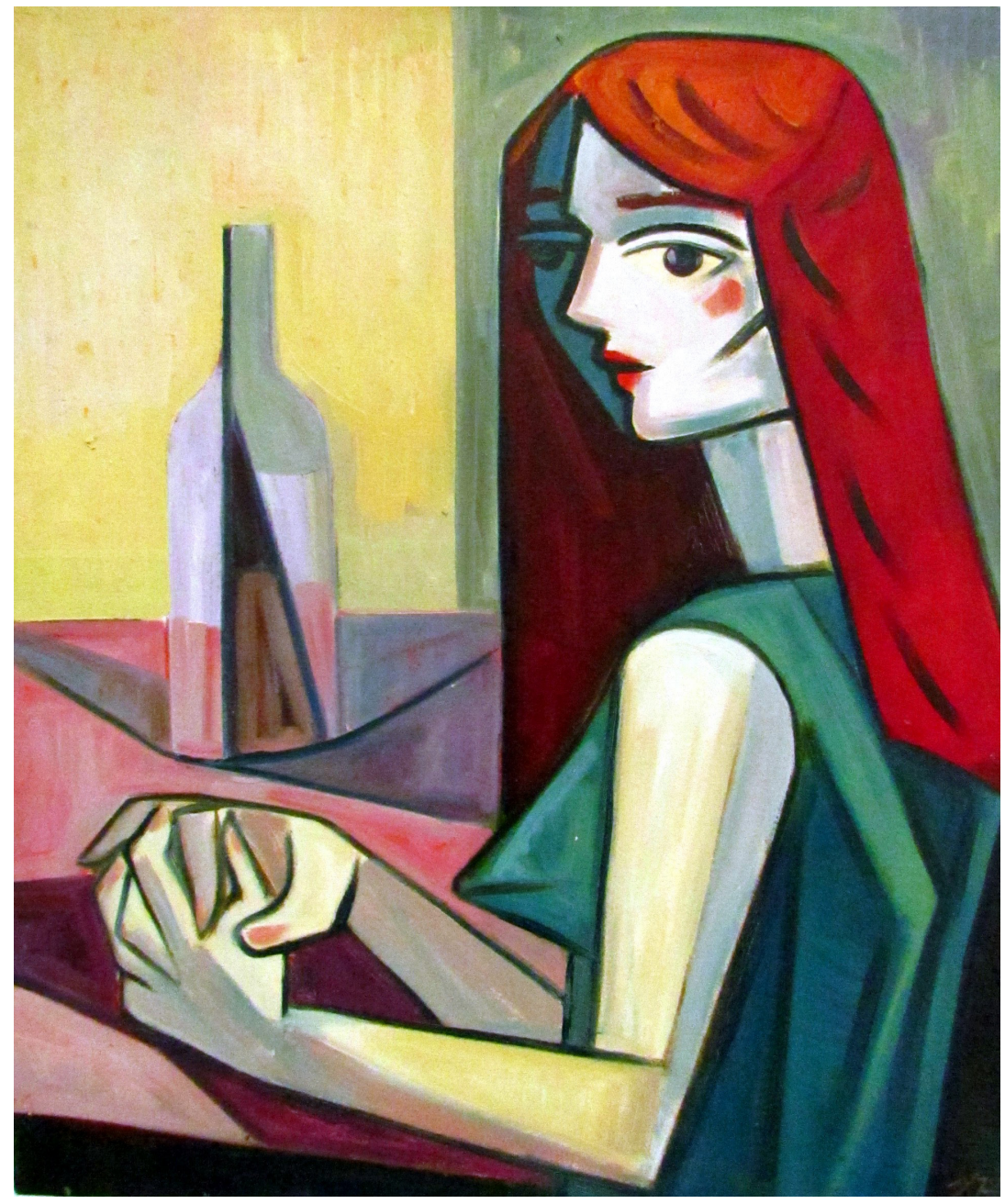

La mujer y la botella. David Ozuna por Andalucía, Petipa vivió un importante acercamiento a la cuna del flamenco: "yo conocí los bailes españoles de la misma fuente original, in situ" (Petipa, Mémoires, 1990).

El repertorio dancístico de esta gira por Andalucía, realizada junto con la bailarina francesa Marie Guy-Stephan, incluyó la coreografía que Petipa creara para ella: el Jaleo de Jerez . Con este Jaleo la bailarina francesa ganó gran admiración tanto de público español como internacional. Sobre la relevancia de este baile español en el repertorio de bailarinas del período del ballet romántico, Eulalia Pablo, académica pionera en el desarrollo de programas de estudio e investigación en el flamenco, resalta:

De cuantos bailes de origen popular subieron a los escenarios teatrales durante el siglo XIX, fue sin duda el Jaleo de Jerez el más popular y el que cosechó los mayores éxitos (Pablo, 1999: 115).

De acuerdo con la investigación de Laura Hormigón, la gira de Petipa con GuyStephan inició en Sevilla el 21 de abril de 1846. A partir de allí, la pareja de bailarines franceses continuó recorriendo Cádiz, Sanlúcar de Barrameda, Málaga, y Granada, regresando a Madrid los últimos días de julio de ese año. Precisamente, en las páginas de sus memorias correspondiente a la narración de esta gira andaluza, Petipa da testimonio de su destreza en el baile andaluz y toque de palillos: "Puedo decir que yo bailaba y tocaba las castañuelas de ninguna manera peor que un auténtico andaluz" (Petipa, Mémoires, 1990).

De hecho, en las memorias de Petipa encontramos datos que testifican que el coreógrafo tocaba las castañuelas desde antes de su estancia en España. Entre sus anécdotas, Petipa explica la estrategia que ideó ante una lesión que le impidió bailar temporalmente justo tras la renovación de su primer contrato como bailarín 
y coreógrafo independiente. Al enterarse que no recibiría sueldo si no participaba escénicamente en la temporada, creó astutamente un espectáculo español en el que participó sin bailar pero tocando las castañuelas, consiguiendo con ello que se le remunerara su trabajo :

...a pesar de que me había roto la pierna cumpliendo mis obligaciones en el escenario los directivos rechazaron realizar cualquier pago... Inventé un nuevo pas español: con las manos le enseñé a la bailarina qué movimientos haría con los pies y yo participaba en este pas acompañando con las castañuelas (Petipa, Mémoires, 1990).

Más adelante, en las páginas de sus memorias dedicadas a su gira andaluza, Petipa relata cómo su llegada a Sanlúcar el 13 de junio de 1946 coincidió con una festividad local donde participó bailando un fandango con la gente del pueblo :

. . bailaban el famoso fandango. Yo llevaba un traje nacional, con el que parecía un auténtico "majo", e invité a una preciosa españolita, y junto con otras tres parejas ejecutamos este típico baile español, que me era bien conocido (Petipa, Mémoires, 1990).

En la descripción de Petipa del entorno de esta festividad confluyen personalidades del toreo, ricos, estudiantes tocando la guitarra, familias asomadas en los balcones y otras paseando. Consecuentemente, estas imágenes las encontramos plasmadas en su ballet Don Quixote, particularmente en el despliegue de personajes del cierre del primer acto que, de acuerdo al libreto, consiste en la llegada de Espada (un matador famoso), los toreros, Mercedes (una bailarina de la calle), el elenco de seguidillas, los gitanos, etcétera.

A través de los testimonios de Petipa, así como de las descripciones plasmadas por viajeros, críticos y periodistas de la época que le vieron bailar, se puede percibir que la calidad dancística española tanto de las coreografías como de la interpretación del entonces joven veinteañero era bastante respetada en España. Desafortunadamente, su picardía, tanto escénica como amorosa, le obligó a dejar la Península. A raíz de ello, Petipa regresó temporalmente a Francia, de donde se trasladó a Rusia, país que le adoptó desde su llegada el 27 de mayo de 1847. Curiosamente, aún en el territorio eslavo, los ballets de temática española marcarían las etapas más significativas de su vida profesional coincidiendo Paquita con su primera intervención escénica (1847), La Estrella de Granada con su primera convocatoria coreográfica (1855) y Don Quixote con su etapa como director artístico del Ballet Imperial (1869).

\section{Posicionamiento de Don} Quixote como icono español en el ballet

Don Quixote de Petipa es ampliamente considerado como el ballet más representativo del baile español por contener tanto bailes de carácter y demi-caractère españoles, como estilizaciones de baile español y de flamenco, pero logrando mantener todo dentro del contexto del ballet clásico. Aún más, el legado artístico cultural que Petipa cosechó a raíz de su fructífera estancia en España le ha posicionado como el coreógrafo de mayor número de coreografías y variaciones de temática española en la historia del ballet, apenas seguido por su compatriota Roland Petit o por el bailarín y coreógrafo español, Víctor Ullate (1947- ), en cuya carrera, formación y obra se ha trenzado tanto el ballet como el flamenco.

Cabe señalar que, a pesar del apoteósico éxito y vigencia en cartelera de Carmen (1949) de Petit, no goza de representaciones comparables a Don Quixote, quizás 
por compartir resonancia con las también magnéticas propuestas coreográficas de la obra literaria de Mérimée firmadas por Alberto Alonso (1967) o Mats Ek (1992). Incluso, el binomio Petipa-Don Quixote ha sobrepasado en cantidad de obra, vigencia y representaciones a coreógrafos y obras tan monumentales como Léonide Massine con El Sombrero de tres picos (1919), o Maurice Béjart con Bolero (1961).

El liderazgo de Petipa tiene mayor rele- vancia al observar la frecuencia con la cual se ha repuesto y presentado no sólo el ballet Don Quixote, sino también variaciones selectas de este, destacando en programas mixtos, galas, y competencias tanto dancísticas como deportivas, especialmente en patinaje artístico o gimnasia rítmica.

En el historial de reposiciones del ballet de esta gran obra de Cervantes, resaltan las aportaciones coreográficas de figuras

Tabla 1 Coreografías de temática española Marius Petipa \& Roland Petit

\begin{tabular}{|l|l|l|}
\hline Marius Petipa & Roland Petit & Víctor Ullate \\
\hline Carmen y su Torero (1846) & Guernica (1945) & Albaicín (1981) \\
\hline La Gitanilla & Carmen (1949) & Sinfonía Sevillana (1982) \\
\hline La Flor de Granada (1843) & España (1961) & La Madrid de Chueca (1982) \\
\hline La Perla de Sevilla (1844) & $\begin{array}{l}\text { Rapsodie Espagnole } \\
\text { (1962) }\end{array}$ & $\begin{array}{l}\text { Yerma (1982) [Homenaje a } \\
\text { Federico] }\end{array}$ \\
\hline $\begin{array}{l}\text { Aventuras de una hija de Madrid } \\
\text { (1844) }\end{array}$ & La Silla (1963) & El Amor Brujo (1994) \\
\hline $\begin{array}{l}\text { Camino a la Corrida de Toros } \\
\text { (1845) }\end{array}$ & $\begin{array}{l}\text { La Danse du Feu } \\
\text { (1983) }\end{array}$ & Jaleos (1996) \\
\hline La Estrella de Granada (1855) & Passacaille (1994) & Don Quixote (1997) \\
\hline $\begin{array}{l}\text { Zoraya, una mora en España } \\
\text { (1881) }\end{array}$ & Le Bolero (1996) & Seguiriya (2000) \\
\hline Don Quijote (1869) & Bolero (2000) & El Sur (2005) \\
\hline Paquita (1846) & & Bolero (2013) \\
\hline Don Juan (1898) & & \\
\hline $\begin{array}{l}\text { Variaciones españolas de otros } \\
\text { ballets: }\end{array}$ & & \\
\hline Lago de los Cisnes (1895) & & \\
\hline Cascanueces (1892) & & \\
\hline Raymonda (1898) & & \\
\hline Coreografías para las óperas: & & \\
\hline Carmen (1882) & & \\
\hline Don Giovani (1898) & & \\
\hline
\end{tabular}


como Mikhail Barishnikov (1978) para el American Ballet Theatre, así como la de Rudolf Nureyev (1966) para la Ópera de Viena. En referencia a la esencia del incipiente flamenco en la obra de Petipa y estas reposiciones, Víctor Ullate defendió su Don Quixote, estrenado en 1997 para conmemorar el 450 aniversario del nacimiento de Cervantes:

Es algo que ya han hecho antes artistas como Nureyev o Barishnikov. Don Quijote es, más que ningún otro, un ballet muy nuestro. Y teniendo en cuenta mis raíces flamencas, he querido darle un aire nuevo, ambientarlo a nuestro país, actualizarlo sin perder la esencia de la coreografía de Petipa, que era un gran conocedor de España y vivió aquí. Pero desde que creó el ballet a finales del siglo pasado, las versiones que se han hecho han estado basadas en tópicos que poco tienen que ver con España o el momento histórico en que se desarrolla (Ullate, 2013:395).

Precisamente, los esfuerzos por resaltar la esencia del legado andaluz de la obra de Cervantes planteada por Petipa, han favorecido la colaboración de maestros y coreógrafos de flamenco en proyectos de reposición, pedagogía y creación. Un ejemplo de estas colaboraciones es la del bailaor y crotalista José de Udaeta quien, en la década de los noventa, colaboró en el montaje de Don Quixote del Staatsoper de Berlín y el de la compañía de ballet de Essen. Sin embargo, en consonancia con el testimonio de Ullate, es importante resaltar que, a pesar de que en este ballet podemos apreciar una amplia procedencia del flamenco, esta es más propia del período pre-flamenco en el que Petipa estuvo en España (1844-1847) que del baile flamenco actual. Independientemente de ello, el ballet Don Quixote ha logrado mantener y transmitir el carácter de la danza española, elemento clave de su esencia, tal como puntualiza la bailarina andaluza, Tamara López, figura del Ballet Nacional de España:

A esas personas que conocen el flamenco o lo han trabajado, esta experiencia les puede brindar la aportación más importante del flamenco a la danza: el carácter (Tamara López, entrevista personal, Sevilla, 2013).

\section{Baile español y flamenco en programas de estudio del ballet}

La establecida presencia del baile español en múltiples contextos del ballet ha hecho indispensable el estudio de su vocabulario, estilización coreográfica, y variaciones de su repertorio. Por tanto, frecuentemente encontramos elementos de este en clases de danzas de carácter, pas de deux y repertorio de escuelas profesionales, compañías y organizaciones dedicadas a la pedagogía de la danza en los cinco continentes, particularmente en organizaciones como la Royal Academy of Dance o el Imperial Society of Teachers of Dancing, las cuales tienen extensa presencia internacional.

De manera concreta, existe toda una serie de pasos de danzas de carácter que se han integrado al syllabus de organizaciones tales como The Choreographic Academy of Dance de Vaganova en Rusia. De hecho, en Character Dance, libro pedagógico sobre las danzas de carácter del programa de esta escuela, se presentan cinco áreas de estudio: rusa, húngara, polaca, gitana y española. Sin embargo, a pesar de existir claras diferencias entre los bailes propios de estas culturas y los bailes de carácter de su procedencia, frecuentemente se dan confusiones al respecto. Joan Lawson, especialista en bailes de carácter y traductora de esta obra, explica que la diferencia entre los bailes autóctonos o folclóricos con respecto a los 
bailes de carácter reside en que éstos últimos son creados para fines teatrales, tal como sucede en ballets como Petrushka y El Tricornio, en los cuales los bailes de carácter aportan colour local a la escena y argumento .

De manera más específica, el capítulo "Studies in Spanish Dance" de esta obra citada, inicia diferenciando dos estilos de danza española en el repertorio escénico: flamenco, al que llama también "gipsy dance," y otro subgénero que llama "classical dance," cuya descripción parece referirse a la Escuela Bolera . Este capítulo señala como características referenciales del flamenco: la improvisación, el uso de castañuelas y el zapateado. Entre los ejercicios, pasos y elementos de estudio planteados en su programa se incluyen ejercicios de zapateado, estilizaciones de pasos del vocabulario del ballet tales como balancés, glissades, y saut de basque, combinaciones de pas de bourrée con renversé, chassé con golpes de pie, pas de basques (cuatro variaciones en su ejecución), pasos realizados arrodillándose y el característico arqueo de espala en las variaciones femeninas de ballets de temática española. Algunos de ellos están ligados específicamente al repertorio de su procedencia, tales como Jota Aragone- sa de Fokine, el Pas de Basque, del cual se especifica que una de sus formas "sólo se encuentra en ballets antiguos (Petipa, Gorsky, etcétera)" y el paso llamado stepping on demi-pointes atribuido a la versión de Loupoukov de Don Quixote .

Tras dar seguimiento a los nombres de los pasos y ejercicios comprendidos dentro del capítulo dedicado a la danza española, podemos observar que más bien se refieren a estilizaciones de pasos del ballet, adoptando elementos similares a los de Escuela Bolera o folklore español, existiendo escasas pinceladas o matices relacionados al flamenco, salvo el estudio relacionado al zapateado. De hecho, en las notas aclaratorias al inicio de Character Dance, Joan Lawson explica que la danza española "es tan variada que poca guía se ofrece respecto a cómo los enchaînements deben de realizarse" .

Asimismo, en filmaciones de las clases de danza de carácter de estilo español de la escuela Vaganova en Rusia se pueden observar estos pasos y sus respectivas características desarrolladas por un entrenamiento específico que permite distinguir el énfasis del sentido de gravedad en el andar, el trabajo del epaulement, acentos expresivos de gestos, floreo de las manos y la línea de brazos en la colocación de la mano en la cadera, como coloquialmente se dice, "en jarras." Entre los accesorios expresivos relacionados con el flamenco, utilizados particularmente en el estudio de danzas de carácter y repertorio de la variación española de Don Quixote, destacan el uso coreográfico del abanico y el manejo de la falda en las bailarinas, así como el despliegue de capote en los bailarines.

\section{Aportaciones del estudio del baile español al repertorio del ballet, consideraciones finales}

Es interesante notar la diferencia en el entrenamiento corporal, la colocación general, la calidad de detalles estilísticos, el 
rango de movimiento, la plasticidad, y la perfección del trabajo del corps de ballet en compañías que incorporan el estudio de las danzas de carácter en el programa de desarrollo profesional de sus escuelas adjuntas de las que adolecen de ello. Esta diferencia de entrenamiento es particularmente palpable en la interpretación del ballet Don Quixote, la cual se puede observar de manera contundente en una muestra comparativa expuesta en la Web que contrapone las versiones del American Ballet Theatre y la del ballet del Kirov en diferentes segmentos . Entre los principios del baile español que se pueden observar en los bailarines del Kirov destacan el uso en espiral del torso, densidad expresiva en el uso de los brazos, colocación de posiciones de brazos acordes a la técnica de baile español, destreza en el manejo del abanico acorde con la línea corporal, expresividad viso-motriz, precisión visual de acentos musicales, calidad dinámica en el fraseo, porte elegante y actitud garbosa.

En cuanto a las aportaciones del flamenco al ballet a nivel técnico, acorde a los beneficios observados en el trabajo de danzas de carácter adicionales al entrenamiento tan meticulosamente diseñado en escuelas profesionales como la de Vaganova, el trabajo contra-lateral y de oposición superior-inferior característico del flamenco amplía la proyección dinámica del port de bras, ofrece mayor equilibrio en secuencias de adagio, y desarrolla mayor estabilidad en giros. Asimismo, este entrenamiento contribuye a elevar el nivel de virtuosismo del bailarín potenciando su dinámica en saltos, particularmente aquellos de petit allegro con gestos de piernas tales como pas de chat y brisé, proporcionando mayor brío, ligereza y suspensión. De manera análoga, el trabajo rítmico, la expresividad en la mirada, el entrenamiento del epaulement y la práctica del trabajo en espiral del torso del flamenco, favorece la velocidad y el equilibrio dinámico en los giros para bailarines de ballet.

Quizás Petipa no pudo imaginar la multiplicidad de aportaciones que su legado coreográfico de ballets de temática española sembraría en el entrenamiento de bailarines, el desarrollo artístico que lograrían quienes se han consagrado como estrellas al explayarse interpretando sus variaciones, ni la larga vida que su obra coreográfica tendría. Sin embargo, este coreógrafo francés, enamorado de España, logró establecer desde el ballet imperial ruso una amplia fuente de recursos que han impulsado al ballet a niveles extraordinarios, motivando colaboraciones con artistas del baile español en el proceso del desarrollo del repertorio de ballets de temática española y, con todo ello, la inclusión de pedagogía tanto de bailes de carácter españoles como de flamenco en las escuelas profesionales de ballet.

Cerramos el telón de este recorrido del legado de ballets de temática española de Marius Petipa dando la palabra a este coreógrafo con esta cita extraída de sus memorias :

Lo expuesto más arriba evidencia que yo conocí los bailes españoles de la misma fuente original, in situ. ¡Pero imagínese! Yo incluí este verdadero, genuino fandango en la ópera Carmen en un escenario de San Petersburgo, donde, lógicamente, tuvo un enorme éxito (Petipa, Mémoires, 1990)

\section{Bibliografía}

Acocella, J., Petipa, M., \& Garafola, L. (September 06, 1994). The Diaries of Marius Petipa. Dance Research: the Journal of the Society for Dance Research, 12, (1.)

Amorós, A., Díez, B. J. M., \& Alvar, C. (1999). Historia de los espectáculos en España. Madrid: Castalia. 
Beaumont, C. W. (1938). Complete book of ballets: A guide to the principal ballets of the nineteenth and twentieth centuries. New York: G.P. Putnam's Sons.

Cervantes, S. M., Suñé, B. J., \& Gil, J. (1942). Don Quijote de la Mancha. Buenos Aires: Librería "El Ateneo".

Clarke, M., \& Crisp, C. (1981). The ballet goer's guide. New York: Knopf.

Gamboa, J. M., \& Núñez, F. (2007). Flamenco de la A a la Z: Diccionario de términos del flamenco. Madrid: Espasa Calpe.

Garafola, L. (n.d.). "Russian ballet in the age of Petipa." En: Kant, M. (2007). The Cambridge companion to ballet. Cambridge: Cambridge University Press. p. 151.

Hormigón, L. (2010). Marius Petipa en España, 1844-1847: Memorias y otros materiales. Madrid: Danzarte Ballet.

Kirstein, L. (1984). Four centuries of ballet: Fifty masterworks. New York: Dover Publications.

Lavaur, L. (1999). Teoría romántica del Cante Flamenco: Raíces flamencas en la coreografía romántica europea. Sevilla: Signatura Ediciones de Andalucía.

Lawson, J. (1964). A history of ballet and its makers. New York: Pitman Pub. Corp.

Lopoukov, A., Shirayev, A., \& Bocharov, A. (1986). Character dance. London: Dance Books.

Lolo, B. (2007). Cervantes y el Quijote en la música: Estudios sobre la recepción de un mito. Alcalá de Henares: Ministerio de Educación y Ciencia, Centro de Estudios Cervantinos.

Martínez del Fresno, B. (2007). El Quijote en el ballet europeo de los siglos XVIII y XIX: de Fuselier a Gorsky. Cervantes y el Quijote en la música: estudios sobre la recepción de un mito.

Matteo. (1990). The language of Spanish dance. Norman: University of Oklahoma Press.

Navarro, G. J. L. (2008). Historia del baile flamenco. Sevilla: Signatura Ediciones de Andalucía.

Pablo, L. E. (1999). Cantes extremeños: Un estudio histórico-descriptivo. Badajoz, Spain: Diputación de Badajoz, Departamento de Publicaciones.

Pablo, L. E., \& Navarro, G. J. L. (2007). Figuras, pasos y mudanzas: claves para conocer el baile flamenco. Córdoba: Almuzara.

Pasi, M., \& Novella, D. J. (1980). El ballet: Enciclopedia del arte coreografico. Madrid: Aguilar.

Petipa, M., Ackerman, G., \& Lorrain, P. (1990). Mémoires. Arles, France: Actes Sud. Ullate, V., \& Guaita, C. (2013). La vida y la danza: Memorias de un bailarín. Madrid: Esfera de los libros. 


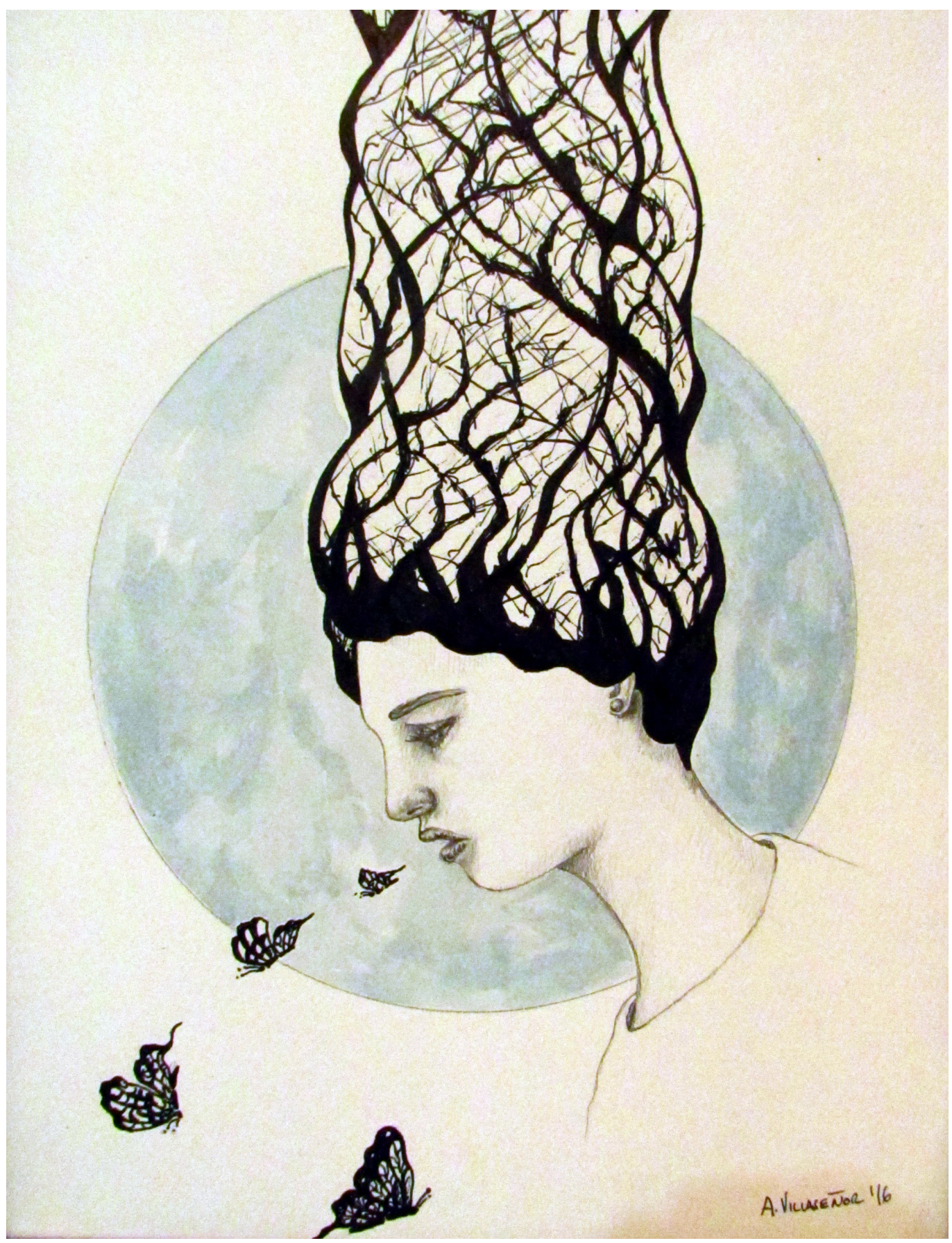

Proyecto II Alicia Villaseñor. 